\title{
Phase equilibria from the exactly integrated Clapeyron equation
}

\author{
Lélio Q. Lobo ${ }^{a}$ and Abel G. M. Ferreira \\ Departamento de Engenharia Química, Universidade de Coimbra, \\ 3030-290 Coimbra, Portugal
}

\begin{abstract}
In this work, the exactly integrated form of the Clapeyron equation found by Mosselman et al. has been used in a systematic manner to derive a comprehensive set of equations describing the first-order transition curves of pure substances. The application of each of these equations requires the knowledge of only one (reference) point on the particular equilibrium line, of the corresponding enthalpy of transition, and some ancillary data (molar volumes and heat capacities of the phases at equilibrium). No fitting to $(p, T)$ experimental data is needed. In this respect the equations developed here can be regarded as a source for calculating a priori the phase equilibrium curves. The results have been tested for a number of selected pure substances of variable molecular complexity, and the uncertainties attached to the calculations have been assessed. Empirical equations currently used for first-order transitions are compared with those obtained from the exact integration. As far as we are aware, no equation was previously proposed for solid + solid equilibrium lines. (C) 2001 Academic Press
\end{abstract}

KEYWORDS: Clapeyron; exact; integration; first-order; transitions

\section{Introduction}

The Clapeyron equation is not an exact differential equation in the mathematical sense. This statement becomes evident if the equation is written in the form

$$
\mathrm{d} p-\left(\Delta_{\alpha}^{\beta} H_{\mathrm{m}} / \Delta_{\alpha}^{\beta} V_{\mathrm{m}}\right) T^{-1} \mathrm{~d} T=0,
$$

where $p$ and $T$ are the natural variables pressure and temperature, $H_{\mathrm{m}}$ and $V_{\mathrm{m}}$ are the molar enthalpy and molar volume of the equilibrium phases, and the symbol $\Delta_{\alpha}^{\beta} X$ indicates the difference between the values of the thermodynamic property $X$ of the two phases at equilibrium $\alpha$ and $\beta$ (e.g. the molar enthalpy for the transition $\alpha \rightarrow \beta$, $\Delta_{\alpha}^{\beta} H_{\mathrm{m}}=H_{\mathrm{m}}^{\beta}-H_{\mathrm{m}}^{\alpha}$ ). Equation (1) governs all first-order phase transitions of pure substances whichever the physical nature of the $(\alpha, \beta)$-pair of phases involved; i.e. $\alpha$ and $\beta$ can be either solid (cr), or liquid (l), or gaseous (g). This equation is useful in

${ }^{a}$ To whom correspondence should be addressed. 
many respects, particularly in the description of the joint rate of change of the primary variables pressure and temperature $(\mathrm{d} p / \mathrm{d} T)$ along the phase equilibrium lines, and also in estimating the derived properties molar enthalpy and molar volume of transition. However, one is frequently interested in knowing the relation between the equilibrium values of $p$ and $T$ instead of their mutual rate of change. This leads to try and integrate equation (1). Since both $H_{\mathrm{m}}$ and $V_{\mathrm{m}}$ are functions of pressure and temperature, and the (mathematically) necessary separation of variables cannot be accomplished in any direct, known manner, the integration of equation (1) has been carried out through approximate methods ever since the equation was first established in the nineteenth century. By making use of thermodynamic cycles Ziegler and his co-workers in a remarkable series of studies devised a method ${ }^{(1)}$ capable of arriving at precise results for a number of selected pure substances. Their work is limited to (solid + gas) and (liquid + gas) equilibria below atmospheric pressure and does not attempt at any general integration of equation (1). It was only in 1982 that Mosselman et al. ${ }^{(2)}$ found the integration factor that transforms the Clapeyron equation into an exact differential equation. By applying the integration factor $\left(T^{-1} \cdot \Delta_{\alpha}^{\beta} V_{\mathrm{m}}\right)$ to equation (1) the Dutch research group obtained

$$
T^{-1} \Delta_{\alpha}^{\beta} V_{\mathrm{m}}(p, T) \mathrm{d} p+\Delta_{\alpha}^{\beta} H_{\mathrm{m}}(p, \mathrm{~T}) \mathrm{d} T^{-1}=0,
$$

which abides by Euler's criterion for exact differentials:

$$
\left\{\partial \Delta_{\alpha}^{\beta} H_{\mathrm{m}}(p, T) / \partial p\right\}_{T}=\left[\partial\left\{T^{-1} \Delta_{\alpha}^{\beta} V_{\mathrm{m}}(p, T)\right\} / \partial T^{-1}\right]_{p} .
$$

Using standard mathematical procedures Mosselman et al. arrived at two solutions for the exact integration of equation (2). For subsequent thermodynamic developments one of the two expressions is clearly preferable for most applications. Since

$$
\left\{\partial \Delta_{\alpha}^{\beta} H_{\mathrm{m}}(p, T) / \partial T\right\}_{p=p_{0}}=\Delta_{\alpha}^{\beta} C_{p, \mathrm{~m}}\left(p_{0}, T\right),
$$

where $C_{p, \mathrm{~m}}\left(p_{0}, T\right)$ is the molar heat capacity at constant pressure $p_{0}$, the necessary substitutions and rearrangements yield the exactly integrated form of Clapeyron equation: ${ }^{(2)}$

$$
\begin{aligned}
T^{-1} \int_{p_{0}}^{p} \Delta_{\alpha}^{\beta} V_{\mathrm{m}}(p, T) \mathrm{d} p & +\int_{T_{0}^{-1}}^{T^{-1}}\left\{\int_{T_{0}}^{T} \Delta_{\alpha}^{\beta} C_{p, \mathrm{~m}}\left(p_{0}, T\right) \mathrm{d} T\right\} \mathrm{d} T^{-1} \\
& =\Delta_{\alpha}^{\beta} H_{\mathrm{m}}\left(p_{0}, T_{0}\right)\left(T_{0}^{-1}-T^{-1}\right) .
\end{aligned}
$$

Mosselman and his co-workers applied this relationship to the vapourization equilibrium of pure substances to extrapolate vapour pressure data and to estimate values of $\Delta_{\alpha}^{\beta} H_{\mathrm{m}}$ at temperatures not too far from the normal boiling point. In our opinion equation (3) can also be used endeavouring rather wider objectives. Since no constraints are imposed in deriving this equation it provides a universal basis to try and work out general equations for all first order phase equilibrium curves of pure substances. The usefulness of this statement relies, of course, on the assumption that a reference point of coordinates $\left(p_{0}, T_{0}\right)$ on each of the equilibrium lines is known, and that suitable analytical forms can be found for the integrand functions $\Delta_{\alpha}^{\beta} V_{\mathrm{m}}(p, T)$ and $\Delta_{\alpha}^{\beta} C_{p, \mathrm{~m}}\left(p_{0}, T\right)$. It is clear from equation (3) that a single value of the molar enthalpy of transition $\Delta_{\alpha}^{\beta} H_{\mathrm{m}}\left(p_{0}, T_{0}\right)$ is needed to carry out the calculations, and therefore no assumptions have to be made concerning the temperature 
and/or pressure dependence of this property. Moreover, and most important, no fitting of $(p, T)$ data for any $(\alpha, \beta)$-phase equilibrium curve needs to be involved.

In the following sections we give account of the assumptions and developments made to establish integrated forms of the equations for first order equilibrium curves, and discuss the results obtained for sublimation, vapourization, fusion, and solid + solid equilibria. (The particular case of liquid + liquid equilibrium has not been examined at this stage.) The testing of the general equations established in this way is also carried out in this work, in which we report on the uncertainties attached to the proposed procedures, and on important thermodynamic quantities derived from those equations. Some of the empirical equations currently used to describe $(p, T)$ transition lines of pure substances are assessed in this context.

\section{Theory}

In this work our main purpose is to derive explicit expressions relating the equilibrium values of the natural variables $p$ and $T$ along the two-phase first-order transition lines of pure substances. The starting point is equation (3), valid for all these transitions. To carry out the necessary integrations one needs to use adequate expressions for the integrand functions $\Delta_{\alpha}^{\beta} V_{\mathrm{m}}(p, T)$ and $\Delta_{\alpha}^{\beta} C_{p, \mathrm{~m}}\left(p_{0}, T\right)$. This means that these functions should satisfy three essential conditions: (i) firstly, both functions should give account as precisely as possible of the pressure and/or temperature dependence of, respectively, the changes in molar volume and in molar heat capacity of the phases involved $(\alpha, \beta \equiv \mathrm{cr}, 1, \mathrm{~g})$ along each of the equilibrium lines; (ii) secondly, the form of these functions should be such that the subsequent integrations in equation (3) can be carried out analytically; and (iii) finally, the number of terms in each of the two mentioned functions should be kept at a minimum compatible with the precision required for the final equations $p=p(T)$, obtained upon integration, to describe the two-phase equilibrium curves.

After careful examination and selection of the experimental data available in the literature for a significant number of molecularly simple (and not so simple) substances the following expressions, which satisfy the three conditions above, were found to be convenient for the representation of the molar volume of the pure phases ${ }^{(3)}$. For the gas phase, we used the (Berlin form of the) virial equation of state truncated after the second term,

$$
V_{\mathrm{m}}^{\mathrm{g}}(p, T)=R T / p+B(T)
$$

where

$$
B(T)=\sum_{i=1}^{m} b_{i} T^{(1-i)},
$$

is the second virial coefficient, the $b_{i}$ being parameters derived from experiment, and $m \leqslant 4$. For the molar volume of saturated condensed phases (liquid or solid) simple polynomial functions were selected. Exception made for the substances that contract on 
melting, the approximation

$$
V_{\mathrm{m}}^{\mathrm{l}, \mathrm{cr}}(p, T) \approx V_{\mathrm{m}}^{\mathrm{l}, \mathrm{cr}}(T)=\sum_{i=1}^{n} v_{i}^{1, \mathrm{cr}} T^{i-1},
$$

works well when the coefficients $v_{i}^{1, c r}$ are obtained from experimental data. In this expression $n \leqslant 3$. In particular, for solid + solid equilibria and for the fusion of substances that expand on melting a single coefficient $v_{1}^{1, \text { cr }}$ suffices. In these cases the molar volume of the condensed phase at the reference point of coordinates $\left(p_{0}, T_{0}\right)$ was taken:

$$
V_{\mathrm{m}}^{1, \mathrm{cr}}(p, T) \approx v_{1}^{1, \mathrm{cr}}=V_{\mathrm{m}}^{1, \mathrm{cr}}\left(p_{0}, T_{0}\right) .
$$

In most of this study (but not always) the triple-point $(\mathrm{cr}+1+\mathrm{g})$ was selected as reference. For solid + liquid equilibria of substances which contract on melting the approach

$$
V_{\mathrm{m}}^{1, \mathrm{cr}}(p, T) \approx V_{\mathrm{m}}^{1, \mathrm{cr}}(p)=\sum_{i=1}^{n} u_{i}^{1, \mathrm{cr}} p^{i-1},
$$

where the coefficients $u_{\mathrm{i}}$ are obtained for experiment, and $n=3$ was found to be adequate. As for the molar heat capacities one has

$$
C_{p, \mathrm{~m}}^{\mathrm{g}}\left(p_{0}, T\right)=C_{p, \mathrm{~m}}^{\mathrm{pg}}(T)-\int_{0}^{p_{0}} T\left(\frac{\partial^{2} V_{\mathrm{m}}^{\mathrm{g}}}{\partial T^{2}}\right)_{p} \mathrm{~d} p,
$$

where the molar heat capacity of the perfect gas $C_{p, \mathrm{~m}}^{\mathrm{pg}}(T)$ is a polynomial function of temperature,

$$
C_{p, \mathrm{~m}}^{\mathrm{pg}}(T)=\sum_{i=1}^{k} c_{i}^{\mathrm{pg}} T^{i-1},
$$

with $k \leqslant 4$. The $c_{i}^{\mathrm{pg}}$ coefficients are easily obtained from spectroscopic data. For saturated condensed phases ( 1 or cr) there is no need to go beyond the approximation

$$
C_{p, \mathrm{~m}}^{\mathrm{l}, \mathrm{cr}}\left(p_{0}, T\right) \approx C_{p, \mathrm{~m}}^{\mathrm{l}, \mathrm{cr}}(T)=\sum_{i=1}^{j} c_{i}^{1, \mathrm{cr}} T^{i-1},
$$

where $j \leqslant 4$ for sublimation, and $j=1$ for all other transitions, i.e.

$$
C_{p, \mathrm{~m}}^{1, \mathrm{cr}}\left(p_{0}, T\right) \approx c_{1}^{1, \mathrm{cr}}=C_{p, \mathrm{~m}}^{1, \mathrm{cr}}\left(p_{0}, T_{0}\right) .
$$

By inserting the analytical expressions given by equations (4)-(12) into equation (3), and carrying out the necessary integrations and algebraic manipulations ${ }^{(3)}$ the following results are obtained for first-order phase equilibria.

(i) Sublimation $(\alpha \equiv \mathrm{cr} ; \beta \equiv \mathrm{g})$ :

$$
\ln p=A_{\mathrm{s}}-B_{\mathrm{S}} / T+C_{\mathrm{s}} \ln T+\sum_{i=2}^{4} D_{\mathrm{s}, i} T^{i-1}+E_{\mathrm{S}}(T) p / T,
$$


where

$$
\begin{aligned}
A_{\mathrm{s}}= & \ln p_{0}+\left\{\Delta_{\mathrm{cr}}^{\mathrm{g}} H_{\mathrm{m}}\left(p_{0}, T_{0}\right)-T_{0} \Delta_{\mathrm{cr}}^{\mathrm{pg}} c_{1} \ln T_{0}-f_{1}\left(T_{0}\right)-T_{0} f_{2}\left(T_{0}\right)-\right. \\
& \left.p_{0} T_{0} v_{2}^{\mathrm{cr}}+p_{0} \sum_{i=2}^{m}(1-i) b_{i} T_{0}^{1-i}\right\} / R T_{0}, \\
B_{\mathrm{s}}= & \left\{\Delta_{\mathrm{cr}}^{\mathrm{g}} H_{\mathrm{m}}\left(p_{0}, T_{0}\right)-f_{1}\left(T_{0}\right)+p_{0} v_{1}^{\mathrm{cr}}-p_{0} \sum_{i=2}^{m} i b_{i} T_{0}^{1-i}\right\} / R, \\
C_{\mathrm{s}}= & \Delta_{\mathrm{cr}}^{\mathrm{pg}} c_{1} / R, \\
D_{\mathrm{s}, i}= & {\left[\left\{\Delta_{\mathrm{cr}}^{\mathrm{pg}} c_{i} / i(i-1)\right\}-p_{0} v_{i+1}^{\mathrm{cr}}\right] / R, } \\
E_{\mathrm{S}}(T)= & \left\{V_{\mathrm{m}}^{\mathrm{cr}}(T)-B(T)\right\} / R .
\end{aligned}
$$

The quantities $f_{1}\left(T_{0}\right)$ and $f_{2}\left(T_{0}\right)$ are given by

$$
\begin{aligned}
& f_{1}\left(T_{0}\right)=\sum_{i=1}^{l} \Delta_{\mathrm{cr}}^{\mathrm{pg}} c_{i} T_{0}^{i} / i, \\
& f_{2}\left(T_{0}\right)=\sum_{i=2}^{l} \Delta_{\mathrm{cr}}^{\mathrm{pg}} c_{i} T_{0}^{i-1} /\{i(i-1)\},
\end{aligned}
$$

where $l \leqslant 4$.

(ii) Vapourization $(\alpha \equiv \mathrm{l} ; \beta \equiv \mathrm{g})$ :

$$
\ln p=A_{\mathrm{v}}-B_{\mathrm{v}} / T+C_{\mathrm{v}} \ln T+D_{\mathrm{v}} T+E_{\mathrm{V}}(T) p / T,
$$

where $A_{\mathrm{v}}$ is obtained from $A_{\mathrm{s}}$ \{equation (14)\}, by changing superscript ${ }^{\mathrm{cr}}$ into ${ }^{1}$, with $f_{2}\left(T_{0}\right)$ $=0$, and by considering only the first term $(i=1)$ in equation (19). For $B_{\mathrm{v}}, C_{\mathrm{v}}$ and $E_{\mathrm{v}}(T)$ similar considerations apply. Of course, all $\Delta_{\mathrm{cr}}^{\mathrm{g}} X$ should be replaced by $\Delta_{1}^{\mathrm{g}} X . D_{\mathrm{v}}$ in equation (21) is given by

$$
D_{\mathrm{v}}=-p_{0} v_{3}^{1} / R \text {. }
$$

(iii) Fusion $(\alpha \equiv \mathrm{cr} ; \beta \equiv 1)$ :

In the case of fusion equilibria two equations were obtained:

$$
p=p_{0}+\left(A_{\mathrm{f}}+D_{\mathrm{f}} T+F_{\mathrm{f}} T \ln T\right) /\left\{\Delta_{\mathrm{cr}}^{1} V_{\mathrm{m}}\left(p_{0}, T_{0}\right)\right\},
$$

for substances which expand on melting, and

$$
\sum_{i=1}^{3}\left(\Delta_{\mathrm{cr}}^{1} u_{i} / i\right)\left(p^{i}-p_{0}^{i}\right)=A_{\mathrm{f}}+D_{\mathrm{f}} T+F_{\mathrm{f}} T \ln T,
$$

if the substances contract on melting. In these two equations,

$$
\begin{aligned}
A_{\mathrm{f}} & =\Delta_{\mathrm{cr}}^{1} c_{1} T_{0}-\Delta_{\mathrm{cr}}^{1} H_{\mathrm{m}}\left(p_{0}, T_{0}\right), \\
D_{\mathrm{f}} & =\Delta_{\mathrm{cr}}^{1} H_{\mathrm{m}}\left(p_{0}, T_{0}\right) / T_{0}-\Delta_{\mathrm{cr}}^{1} c_{1}\left(1+\ln T_{0}\right), \\
F_{\mathrm{f}} & =\Delta_{\mathrm{cr}}^{1} c_{1} .
\end{aligned}
$$


Equations (23) and (24) both reduce to the same linear equation

$$
p=A+D T,
$$

where $A$ and $D$ are constants, when $\Delta_{\mathrm{cr}}^{1} u_{i}=0$ for $i=2,3$, and $\Delta_{\mathrm{cr}}^{1} c_{1}=0$, an oversimplification not necessary to deal with fusion.

(iv) Solid + solid equilibria $(\alpha \equiv \operatorname{crI} ; \beta \equiv \operatorname{crII})$ :

For solid + solid equilibria the resulting expression has analytical form identical to equation (23), where the changes $\Delta_{\alpha}^{\beta} X$ in equations (25)-(27) are now defined as $\Delta_{\alpha}^{\beta} X=$ $\Delta_{\mathrm{crI}}^{\mathrm{crI}} X$. Sometimes, in consequence of the lack of extensive high-temperature data, it may prove necessary to use simplified versions of equation (23) which is sufficiently flexible to admit approximations going as farther as its simplest form, equation (28).

\section{Results and discussion}

Having obtained explicit expressions for the equilibrium curves on $(p, T)$ phase diagrams - equations (13), (21), (23), and (24) — it seemed worth examining their range of application, and the relative importance of the terms involved in each of them. A group of 24 substances on which accurate thermodynamic data were found in the literature was selected $^{(3)}$ to test the equations derived in the previous sections. This set includes both organic and inorganic substances, of polar and non-polar molecules, and of complexity ranging from simple monatomic species - the rare gases and some metals - to aromatic hydrocarbons. According to the nature and availability of the data, subsets from the wider group of substances were selected to test each of the equilibrium equations above. Whenever possible the temperature scales in the original papers were transformed into ITS-90 by recommended techniques. ${ }^{(4)}$

\section{SUBLIMATION}

In most cases accurate molar volumes of the solid phases were assessed from lowtemperature X-ray measurements of the lattice parameters as functions of temperature. However, it was found that in no case such values contribute significantly to the calculated sublimation pressure. Therefore, they can be dropped from equations (14), (15), (17), and (18). The influence of second virial coefficients on the quantity $E_{\mathrm{S}}(T)$ \{cf. equation (18)\} is significant only when the pressure of the reference point $p_{0}$ is relatively high, as is the case with carbon dioxide. Since for most substances $\left(p_{0}, T_{0}\right)$ have been taken as the triple-point coordinates, term $\left\{E_{\mathrm{S}}(T) p / T\right\}$ in equation (13) can be neglected whenever the triple-point pressure is low $\left(p_{0}<10 \mathrm{kPa}\right)$. Apart from this all the remaining terms in equation (13) should be taken into account. In absolute value

$$
C_{\mathrm{s}} \ln T>B_{\mathrm{s}} / T>\sum D_{\mathrm{s}, \mathrm{i}} T^{i-1} \text {. }
$$

Term $A_{\mathrm{s}}$, which is a positive constant, is smaller than (the absolute of) terms involving $C_{\mathrm{s}}$ and $B_{\mathrm{s}}$. The quantities $\left(C_{\mathrm{s}} \ln T\right)$ and $\left(B_{\mathrm{S}} / T\right)$ are positive, while the summation including $D_{\mathrm{s}, i}$ is negative in every case. All these contributions are relatively important in magnitude, although considerable partial cancelation between them always occurs. The value of the 


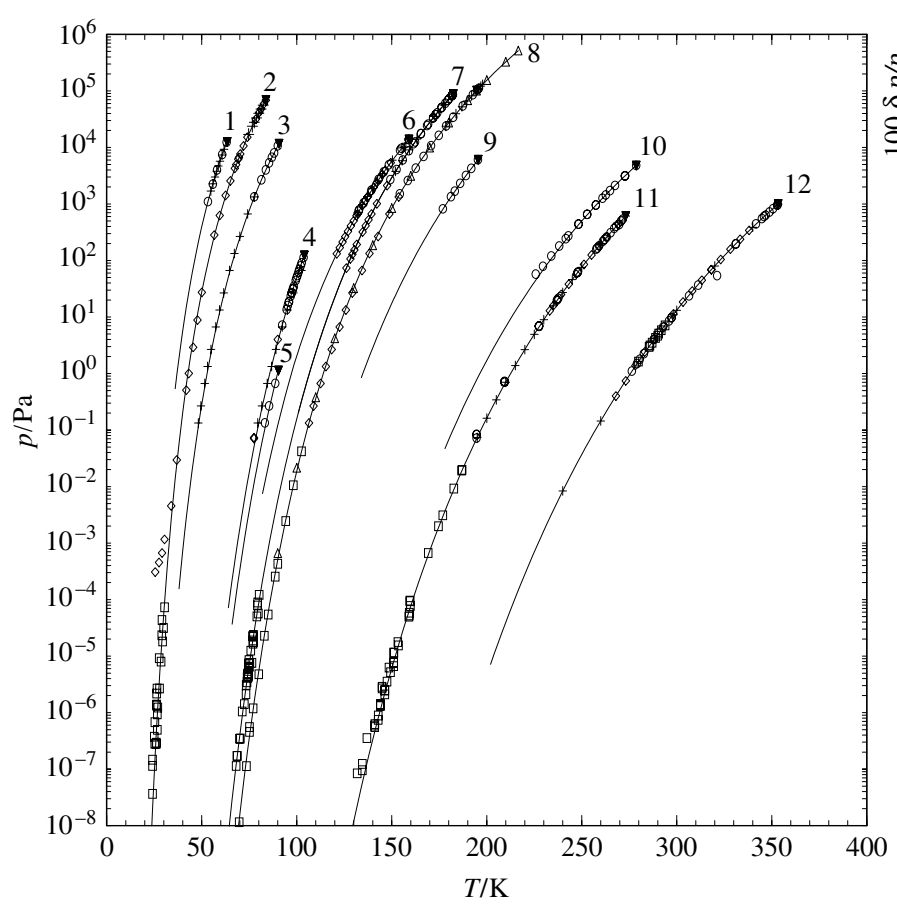

a
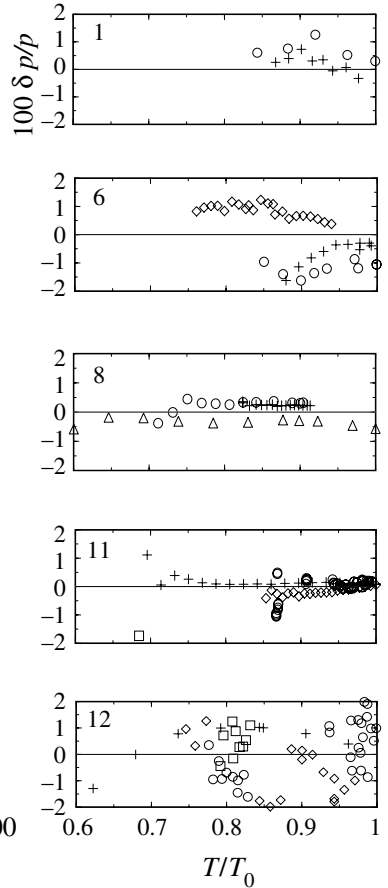

b

FIGURE 1. a, Sublimation pressure $p$ plotted against temperature $T$. b, Deviation plot of the plotted against temperature $T$. b, Deviation plot of the sublimation pressure against a reduced temperature $\left(T / T_{0}\right) ; \delta p=p_{\text {calc }}-p$, where $p_{\text {calc }}$ is calculated from equation (13) and $p$ is the experimental sublimation pressure at the same temperature; $T_{0}$ is the temperature of the reference point, taken as $T_{\mathrm{tr}}$ for all substances in the plot except carbon dioxide, for which $T_{0}$ was considered to be the normal sublimation temperature. Legend: curves obtained from equation (13); $\mathbf{\nabla}$, triple-points from Staveley et al. ${ }^{(5)} ; 1$, nitrogen: $\mathrm{O}$, Keesom and $\mathrm{Bijl}^{(6)} ;+$, Giauque and Clayton ${ }^{(7)} ; 2$, argon: O, Flubacher et al $^{\left({ }^{(8)} ;+ \text {, Chen } \text { et al. }{ }^{(9)} ; \diamond \text {, Lemming and Pollack }\right.}{ }^{(10)} ; \square$, Levenson ${ }^{(11)} ; 3$, methane: $\mathrm{O}$, Tickner and Lossing ${ }^{(12)} ;+$, Rossini ${ }^{(13)} ; 4$, ethylene: $\mathrm{O}$, Bigleisen et al. ${ }^{(14)} ;+$, Chu Liang ${ }^{(15)}$; 5 , ethane: $\bigcirc$, Tickner and Lossing ${ }^{(12)} ; 6$, hydrogen chloride: $\bigcirc$, Giauque and Wiebe ${ }^{(16)} ;+$, Chihara and Inaba ${ }^{(17)} ; \diamond$, Ser and Larher ${ }^{(18)} ; 7$, dinitrogen oxide: $\bigcirc$, Atake and Chihara ${ }^{(19)} ;+$, Blue and Giauque $^{(20)} ; \diamond$, Terlain ${ }^{(21)} ; \square$, Bryson et al. ${ }^{(22)} ; 8$, carbon dioxide: $\bigcirc$, Giauque and Egan ${ }^{(23)}$; + , Tickner and Lossing ${ }^{(12)} ; \diamond$, Ambrose ${ }^{(24)} ; \square$, Bryson et al. ${ }^{(22)} ; \triangle$, Angus et al. ${ }^{(25)} ; 9$, ammonia: O, Overstreet and Giauque ${ }^{(26)} ; 10$, benzene: $O$, Jackowski ${ }^{(27)} ; 11$, water: $\mathrm{O}$, Jancso et al. ${ }^{(28)}$; + , Ambrose ${ }^{(29)} ; \diamond$, Keenan et al. ${ }^{(30)} ; \square$, Bryson et al. ${ }^{(22)} ; 12$, naphtalene: O, De Kruif et al. ${ }^{(31)}$; + , Bradley and Cleasby ${ }^{(32)} ; \diamond$, Ambrose et al. ${ }^{(33)} ; \square$, Sinke ${ }^{(34)}$.

enthalpy of sublimation at the reference point $\Delta_{\mathrm{cr}}^{\mathrm{g}} H_{\mathrm{m}}\left(p_{0}, T_{0}\right)$ carries the main contribution to $A_{\mathrm{s}}$ and $B_{\mathrm{s}}$. For this reason $\Delta_{\mathrm{cr}}^{\mathrm{g}} H_{\mathrm{m}}\left(p_{0}, T_{0}\right)$ should be known as accurately as possible if precise estimates of the sublimation pressure are aimed at. Uncertainties of $\pm 0.1 \mathrm{~K}$ in $T_{0}$, and of \pm 1 per cent in $C_{p, \mathrm{~m}}^{\mathrm{cr}}$ and $C_{p, \mathrm{~m}}^{\mathrm{pg}}$ have negligible influence (of less than 1 per cent) on 
the calculated sublimation pressure, down to temperatures as low as $0.5 \cdot T_{0}$ or even lower. In general the equilibrium pressures estimated through equation (13) lay within about \pm 1 per cent of the corresponding experimental values even at the lowest temperatures at which measurements have been reported, as figure 1 suggests. It is important to emphasize that these results were obtained from the knowledge of the reference point coordinates $\left(p_{0}, T_{0}\right)$, and the information required by equations (14) to (20), with no need of any other experimental points on the sublimation curve. The equilibrium pressure calculations start at any adequate reference point $\left(p_{0}, T_{0}\right)$ proceeding to lower temperatures if the reference is the triple-point $(\mathrm{cr}+\mathrm{l}+\mathrm{g})$. For substances exhibiting more than one solid phase, when a solid + solid transition is reached the coordinates of the corresponding transition point should be taken as new reference for the subsequent calculation of the sublimation pressure of the lower-temperature solid form. Of course, the molar enthalpy of the particular solid $\rightarrow$ solid transition $\Delta_{\mathrm{crI}}^{\mathrm{crI}} H_{\mathrm{m}}$ must be taken into account through the exact relationship,

$$
\Delta_{\mathrm{crI}}^{\mathrm{g}} H_{\mathrm{m}}=\Delta_{\mathrm{crII}}^{\mathrm{g}} H_{\mathrm{m}}+\Delta_{\mathrm{crI}}^{\mathrm{crII}} H_{\mathrm{m}}
$$

at the new reference point.

The molar enthalpy of sublimation as a function of temperature is obtained from Clapeyron equation by using equation (13) in the calculation of $(\mathrm{d} p / \mathrm{d} T)$. After algebraic rearrangements the following expression is obtained: ${ }^{(3)}$

$$
\Delta_{\mathrm{cr}}^{\mathrm{g}} H_{\mathrm{m}}=R\left[B_{\mathrm{s}}+C_{\mathrm{s}} T+\sum_{i=2}^{4}(i-1) D_{\mathrm{s}, i} T^{i}+\left\{\mathrm{d} E_{\mathrm{s}}(T) / \mathrm{d} T\right\} p T^{2}\right] .
$$

When two or more solid phases are present the calculation of the enthalpy of sublimation as function of temperature must take equation (29) into account. In figure 2 the results of our estimates of $\Delta_{\mathrm{cr}}^{\mathrm{g}} H_{\mathrm{m}}(T)$ are compared with data from the literature. The enthalpy of sublimation is markedly dependent on temperature (changes of up to 15 per cent over the sublimation range), exhibiting a maximum for every substance. It can be shown ${ }^{(3)}$ that the maximum of $\Delta_{\mathrm{cr}}^{\mathrm{g}} H_{\mathrm{m}}$ always occurs at the temperature for which the molar heat capacities of the solid and gaseous phases are equal, i.e. when $C_{p, \mathrm{~m}}^{\mathrm{cr}}=C_{p, \mathrm{~m}}^{\mathrm{g}}$. It may be interesting to note that for all hydrocarbons in the test group of substances the maxima are observed at $T=(52.2 \pm 0.7) \mathrm{K}$. In no case does the deviation between the calculated values of $\Delta_{\mathrm{cr}}^{\mathrm{g}} H_{\mathrm{m}}$ and the literature ones exceed \pm 0.5 per cent. The uncertainty in the estimated $\Delta_{\mathrm{cr}}^{\mathrm{g}} H_{\mathrm{m}}(T)$ comes mainly from the uncertainty attached to the (experimental) values of $\Delta_{\mathrm{cr}}^{\mathrm{g}} H_{\mathrm{m}}\left(p_{0}, T_{0}\right)$. The enthalpy of sublimation at $T \rightarrow 0$, closely related to the so-called lattice cohesion energy - a quantity of interest in the study of intermolecular forces, and otherwise - is also readily assessed. In fact, from equation (30), at $T \rightarrow 0$ one has:

$$
\Delta_{\mathrm{cr}}^{\mathrm{g}} H_{\mathrm{m}}(0 \mathrm{~K})=R B_{\mathrm{s}}
$$

Table 1 summarizes the results obtained for $\Delta_{\mathrm{cr}}^{\mathrm{g}} H_{\mathrm{m}}(0 \mathrm{~K})$ using equation (31), and compares them with literature values. The agreement is striking. For linear hydrocarbons $\Delta_{\mathrm{cr}}^{\mathrm{g}} H_{\mathrm{m}}(0 \mathrm{~K})$ seems to be a linear function of the number of carbon atoms $n_{\mathrm{c}}$ in the chain,

$$
\Delta_{\mathrm{cr}}^{\mathrm{g}} H_{\mathrm{m}}(0 \mathrm{~K}) /\left(\mathrm{kJ} \cdot \mathrm{mol}^{-1}\right)=2.90+7.95 n_{c} .
$$

The slope is close to that suggested by Moelwyn-Hughes. ${ }^{(56)}$ 


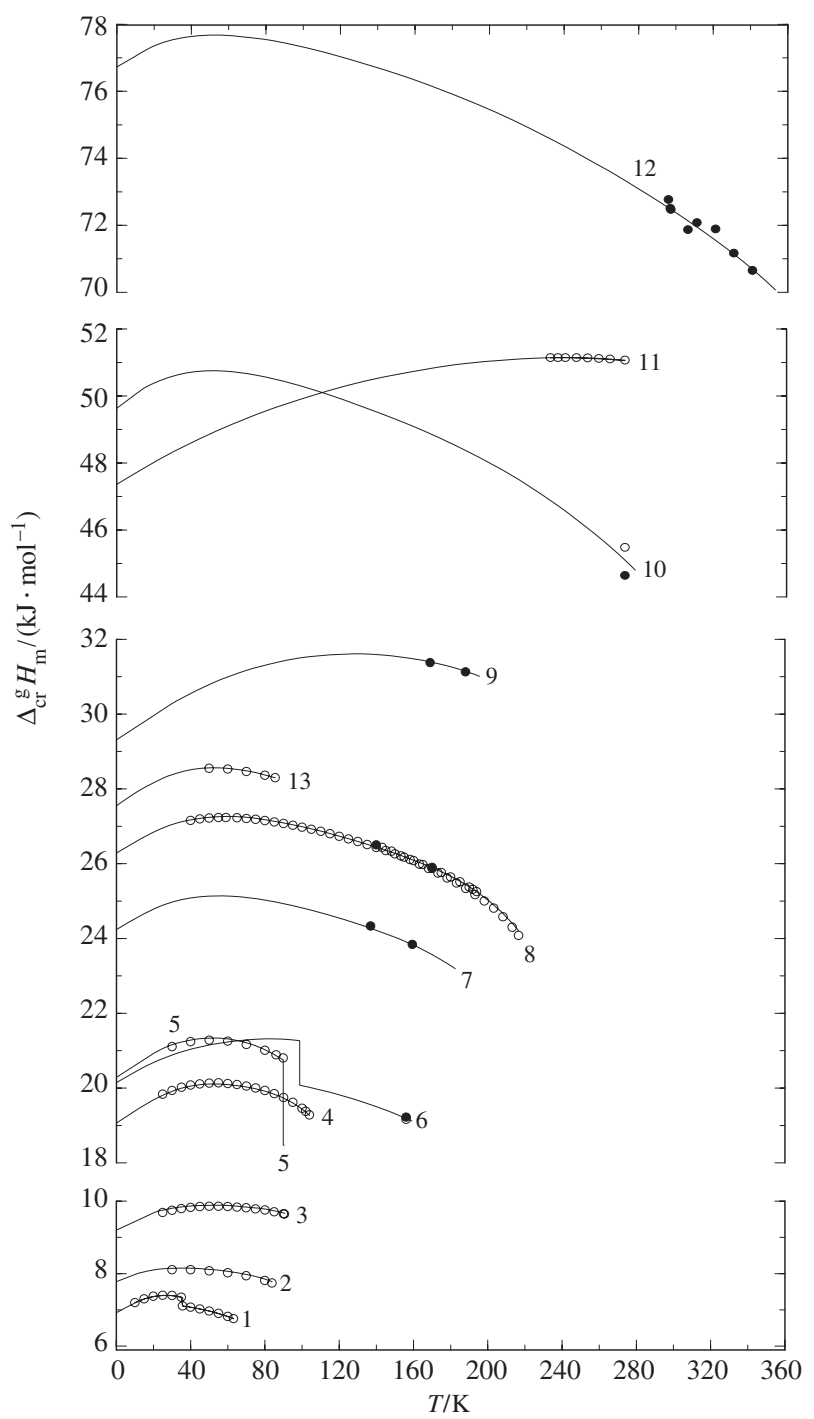

FIGURE 2. Molar enthalpies of sublimation $\Delta_{\mathrm{cr}}^{\mathrm{g}} H_{\mathrm{m}}$ of pure substances plotted against temperature $T$. Legend: curves obtained from equation (30). - and $\bigcirc$ are values from the literature; the full circles are experimental, and the open circles are calculated; 1, nitrogen: O, Ziegler et al. ${ }^{(35)} ; 2$, argon: O, Ziegler et al. ${ }^{(36)} ; 3$, methane: O, Ziegler et al. ${ }^{(37)}$; 4, ethylene: O, Ziegler et al. ${ }^{(1)} ;$, ethane: $\bigcirc$, Ziegler et al. ${ }^{(38)} ; 6$, hydrogen chloride: $\bullet$, Eucken and Donath $^{(39)}$; O, Giauque and Wiebe ${ }^{(16)} ; 7$, dinitrogen oxide: $\bullet$, Eucken and Donath ${ }^{(39)} ; 8$, carbon dioxide: $\bullet$, Eucken and Donath ${ }^{(39)}$; O, Giauque and Egan ${ }^{(23)}$; Mullins et al. ${ }^{(40)}$; Newitt et al. ${ }^{(41)}$; 9, ammonia: $\bullet$ Eucken and Donath ${ }^{(39)}$; 10, benzene: $\bullet$, De Boer ${ }^{(42)}$; O, Jackowski ${ }^{(27)}$; 11, water: O, Keenan et al. ${ }^{(30)} ; 12$, naphtalene: $\bullet$, Murata et al. ${ }^{(43)} ; 13$, propane: $\bigcirc$, Yarbrough and Tsai ${ }^{(44)}$. 
TABLE 1. Molar entalphy of sublimation $\Delta_{\mathrm{cr}}^{\mathrm{g}} H_{\mathrm{m}}$ of pure substances at $T=0 \mathrm{~K}$

\begin{tabular}{|c|c|c|c|}
\hline \multicolumn{2}{|c|}{ Substance } & \multicolumn{2}{|c|}{$\Delta_{\mathrm{cr}}^{\mathrm{g}} H_{\mathrm{m}}(0 \mathrm{~K}) /\left(\mathrm{J} \cdot \mathrm{mol}^{-1}\right)$} \\
\hline & & This work & Literature \\
\hline 1 & Nitrogen & 6883 & $\begin{array}{l}6925 \pm 20^{(45)} \\
6861^{(46)}\end{array}$ \\
\hline 2 & Argon & 7733 & $\begin{array}{l}7724 \pm 29^{(47)} \\
7740 \pm 50^{(48,49)}\end{array}$ \\
\hline 3 & Methane & 9199 & $\begin{array}{l}9168^{(50)} \\
9360 \pm 21^{(51)}\end{array}$ \\
\hline 4 & Ethylene & 19060 & $19096^{(52)}$ \\
\hline 5 & Ethane & 20090 & \\
\hline 6 & Hydrogen chloride & 20078 & $20222^{(18)}$ \\
\hline 7 & Dinitrogen oxide & 24149 & $\begin{array}{l}24210^{(19)} \\
24263 \pm 21^{(21)}\end{array}$ \\
\hline 8 & Carbon dioxide & 26190 & $\begin{array}{l}26250 \pm 90^{(25)} \\
26229^{(53)} \\
26222^{(41)}\end{array}$ \\
\hline 9 & Ammonia & 29220 & $28870^{(54)}$ \\
\hline 10 & Benzene & 49684 & \\
\hline 11 & Water & 47348 & $47346 \pm 17^{(55)}$ \\
\hline 12 & Naphthalene & 76651 & \\
\hline 13 & Propane & 27431 & \\
\hline
\end{tabular}

\section{VAPOURIZATION}

Most of the considerations made for the sublimation curve, equation (13), apply to equation (21) which governs the vapour pressure curve. However, the term $\left\{E_{\mathrm{V}}(T) p / T\right\}$, which is always positive, is not negligible for the vapourization equilibrium due to the relatively higher contribution of the second virial coefficient and the vapour pressure. For the test substances in this study neglecting term $\left(D_{\mathrm{v}} T\right)$ in equation $(21)$ introduces a maximum error of 0.4 per cent in the calculated vapour pressure at the critical temperature. This is a consequence of the comparatively small values of $v_{3}^{1}$ parameters in equation (22). By ignoring $\left(D_{\mathrm{v}} T\right)$ in equation (21) it becomes,

$$
\ln p=A_{\mathrm{v}}-B_{\mathrm{v}} / T+C_{\mathrm{v}} \ln T+E_{\mathrm{v}}(T) p / T,
$$

formally identical to the equation proposed by $\mathrm{Graetz}^{(57)}$ in 1903 . The approximation made by introducing equation (12) is a consequence of the lack of experimental data for $C_{p, \mathrm{~m}}^{\mathrm{l}}$ over wide temperature ranges. However, this approximation is not critical because liquid molar heat capacities are weak functions of temperature. Since in the vapour pressure calculations the normal boiling point is a convenient choice for the reference coordinates 
$\left(p_{0}, T_{0}\right)$, the values of $C_{p, \mathrm{~m}}^{1}$ at that point (which are known from experiment with sufficient accuracy) have been used in equation (12). For the liquid molar volumes the coefficients $v_{i}^{1}$ in equation (6) were obtained by fitting to experimental data usually extending from the triple-point up to reduced temperatures of about $T_{\mathrm{r}}=T / T_{\mathrm{c}}=0.75$ along the saturation line. $T_{\mathrm{c}}$ is the critical temperature. In the present approach we did not use critical exponents for the molar volumes in order to keep the mathematical complexities at a minimum. This means that in describing the vapour pressure curve near the critical point some room for improvement clearly exists. In spite of the approximations made the mean relative deviation in the estimated vapour pressure for most of the test substances is less than \pm 1 per cent up to about $T_{\mathrm{r}}=0.95$, as illustrated in figure 3 . As for the influence of the uncertainties attached to the ancillary data needed in the vapour pressure calculations using equation (21), uncertainties of \pm 2 per cent in the second virial coefficient and of \pm 1 per cent in $V_{\mathrm{m}}^{1}, C_{p, \mathrm{~m}}^{\mathrm{l}}$, and $C_{p, \mathrm{~m}}^{\mathrm{pg}}$ lead (each of them) to deviations in $p$ of less than \pm 1 per cent of the experimental vapour pressure, from the triple-point temperature up to about $T_{\mathrm{r}}=0.95$ for most of the substances in the subset. In no case these deviations are larger than \pm 2 per cent. The error introduced in the calculated vapour pressure by an uncertainty as large as $0.1 \mathrm{~K}$ in the value of the reference point temperature $\left(T_{0}\right)$ is less than \pm 1 per cent over the complete vapour + liquid equilibrium line (i.e. from the triple-point temperature $T_{\mathrm{tr}}$ up to $T_{\mathrm{c}}$ ) if $T_{0}>100 \mathrm{~K}$, as is the case for most substances considered here. An error of \pm 1 per cent in the value of $\Delta_{1}^{\mathrm{g}} H_{\mathrm{m}}\left(p_{0}, T_{0}\right)$ can rise deviations in the calculated vapour pressure as high as \pm 5 per cent for temperatures from about $T_{\mathrm{r}}=0.40$ to about $T_{\mathrm{r}}=0.85$. For this reason values of the enthalpy of vapourization at the normal boiling temperature estimated through current empirical methods (cf. Reid et al. ${ }^{\left({ }^{84}\right)}$ ) should not be recommended to be used in accurate applications of equation (21). Fortunately for most substances of interest $\Delta_{1}^{\mathrm{g}} H_{\mathrm{m}}$ at that temperature is known with much lower uncertainty, typically of about \pm 0.1 (or 0.2 ) per cent from accurate experimental work, and this leads to deviations from that source not exceeding \pm 1 per cent in the vapour pressure up to the critical temperature.

It is interesting to compare the form of equation (21) with some of the current empirical vapour pressure equations suggested by approximate methods of integration of the Clapeyron equation. The equations named after Wrede, ${ }^{(57,85)}$ Rankine-Kirchhoff, ${ }^{(57,85)}$ van Laar, ${ }^{(57)}$ Honnig and Hook, ${ }^{(86)}$ and Cragoe, ${ }^{(85,87)}$ respectively,

$$
\begin{aligned}
& \ln p=A-B / T, \\
& \ln p=A-B / T+C \ln T, \\
& \ln p=A-B / T+C \ln T+D T, \\
& \ln p=A-B / T+C \ln T+D_{1} T+D_{2} T^{2}, \\
& \ln p=A-B / T+D_{1} T+D_{2} T^{2},
\end{aligned}
$$

are, of course, particular forms of equation (21) — as already pointed out, at least in part, by Mosselman et al. ${ }^{(2)}$ — while the empirical equations of Graetz ${ }^{(57)}$ and Frost-Kalkwarf, ${ }^{(88)}$

$$
\ln p=A-B / T+C \ln T+E p / T,
$$




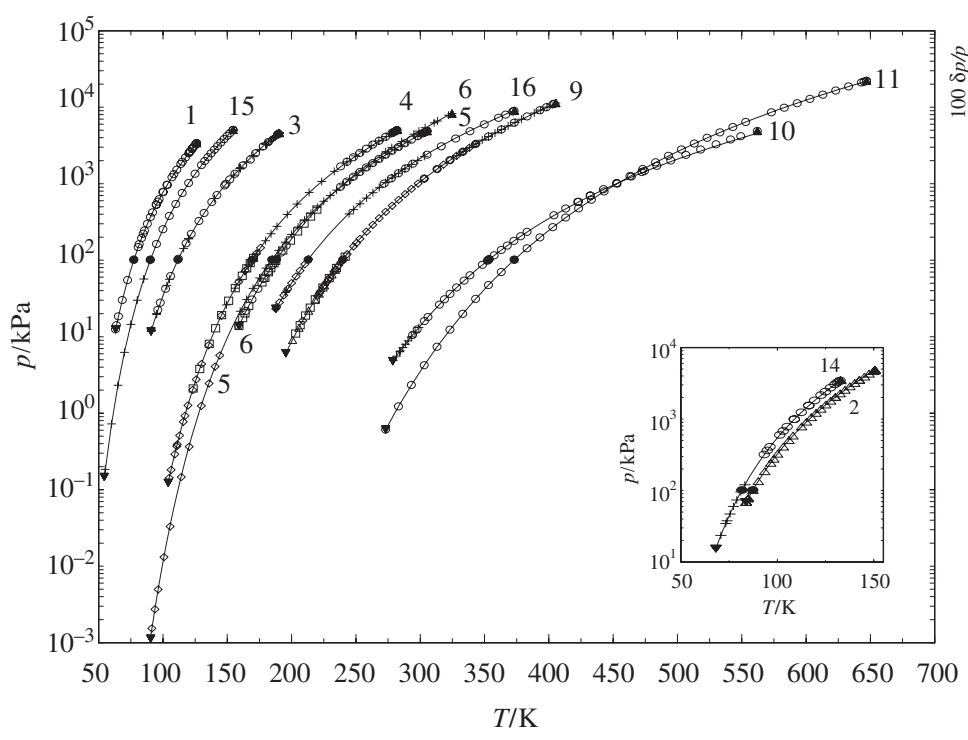

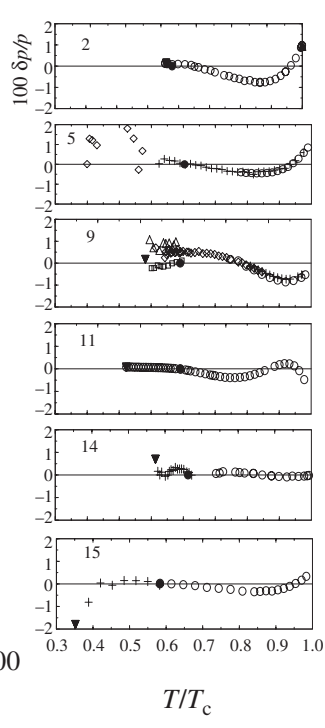

b

FIGURE 3. a, Vapour pressure $p$ as a function of temperature $T$. Note the different scales on the insert. $\mathrm{b}$, Deviation plot of the vapour pressure against reduced temperature $T_{\mathrm{r}}=T / T_{\mathrm{c}}$; $\delta p=p_{\text {calc }}-p$, where $p_{\text {calc }}$ is calculated from equation (21) and $p$ is the experimental vapour pressure at the same temperature. Legend: curves obtained from equation (21). $\mathbf{\nabla}$, triple-points from Staveley et al. ${ }^{(5)} ; \boldsymbol{\Lambda}$, critical points from various authors; $\bullet$, normal boiling points (whose temperature $T_{b}$ as been taken as reference $T_{0}$ ) from various authors; 1 , nitrogen: $\mathrm{O}$, Wagner ${ }^{(58)} ; 2$, argon: $\triangle$, Wagner ${ }^{(58)} ; 3$, methane: $\bigcirc$, Kleinrahm and Wagner ${ }^{(59)} ;+$, Prydz and Goodwin ${ }^{(60)} ; 4$, ethylene: $\bigcirc$, Douslin and Harrison ${ }^{(61)} ;+$, Michels and Wassenaar ${ }^{(62)} ; \diamond$, Bigeleisen et al. ${ }^{(14)}$; $\square$, Egan and Kemp ${ }^{(63)} ; 5$, ethane: $O$, Douslin and Harrison ${ }^{(64)} ;+$, Straty and Tsumura ${ }^{(65)}$; $\diamond$, Carruth and Kobayashi ${ }^{(66)} ; 6$, hydrogen chloride: +, Thomas ${ }^{(67)} ; \square$, Henderson et al. ${ }^{(68)}$; $\bigcirc$, Giauque and Wiebe ${ }^{(16)} ; 9$, ammonia: $\bigcirc$, Beattie and Lawrence ${ }^{(69)} ;+$, Baehr et al. $^{(70)} ; \diamond$, Cragoe et al. ${ }^{(71)} ; \square$, Overstreet and Giauque ${ }^{(26)} ; \triangle$, Streatfeild et al. ${ }^{(72)} ; 10$, benzene: $\bigcirc$, Ambrose ${ }^{(73,74)}$; + , Golding and Machin ${ }^{(75)} ; 11$, water: O, Sato et al. ${ }^{(76)} ; 14$, carbon monoxide: O, Michels et al. ${ }^{(77)}$; + , Clayton and Giauque ${ }^{(78)}$; 15, oxygen: $O$, Wagner et al. ${ }^{(79)} ;+$, Hilsenrath ${ }^{(80)} ; 16$, hydrogen sulphide: $\bigcirc$, Kay and Rambosek ${ }^{(81)} ;+$, Clarke and Glew ${ }^{(82)} ; \diamond$, Giauque and Blue ${ }^{(83)}$.

$$
\ln p=A-B / T+C \ln T+E p / T^{2},
$$

respectively, both derived on the assumption that the vapour phase is a van der Waals gas, show different dependences on temperature in the last term. In all these equations the empirical parameters $A, B, C, D, D_{i}$, and $E$ ought to be determined by fitting to vapour pressure measurements, while the calculation of the corresponding parameters in equation (21) is made a priori requiring the knowledge of only one point on the vapour pressure curve - the reference point $\left(p_{0}, T_{0}\right)$-and the above mentioned ancillary data. It should be noted that $E_{\mathrm{v}}(T)$ in equations (21) and (33) is temperature dependent. 
The coefficients in the polynomial expression chosen to represent the change in the molar volume of the liquid with temperature $\{\mathrm{cf}$. equation (6)\} were obtained by fitting to experimental values up to $T_{\mathrm{r}}=0.75$, as said. This limits the accuracy of equation (21) in estimating the molar enthalpy of vapourization beyond that temperature, up to $T_{\mathrm{c}}$. To overcome this insufficiency an alternative method has been developed. Since from the Clapeyron equation $\Delta_{1}^{\mathrm{g}} H_{\mathrm{m}}$ is given as

$$
\Delta_{1}^{\mathrm{g}} H_{\mathrm{m}}=R T^{2} \Delta_{1}^{\mathrm{g}} Z \cdot(\mathrm{d} \ln p / \mathrm{d} T),
$$

where $\left(Z=p V_{\mathrm{m}} / R T\right)$ is the compressibility factor, an attempt was made to try and find a generalized expression for $\Delta_{1}^{\mathrm{g}} Z$ as function of the reduced variables $p_{\mathrm{r}}$ and/or $T_{\mathrm{r}}$ along the saturation line. This led to:

$$
\Delta_{1}^{\mathrm{g}} Z=z_{0}\left(1-p_{r}\right)^{0.32}+\sum_{w=1}^{3} z_{w}\left(1-p_{\mathrm{r}}\right)^{w},
$$

where $z_{0}=0.4635, z_{1}=0.6186, z_{2}=-0.5784$, and $z_{3}=0.4815$, valid over the complete liquid range. In this way accurate estimates of $\Delta_{\mathrm{l}}^{\mathrm{g}} H_{\mathrm{m}}$ from $T_{\mathrm{tr}}$ to $T_{\mathrm{c}}$ can be made by using equation (41) in conjunction with equation (42) for $\Delta_{1}^{\mathrm{g}} Z$, and equation (21) to calculate $(\mathrm{d} \ln p / \mathrm{d} T)$.

\section{FUSION}

We have not been able to devise a general treatment of fusion equilibria capable of achieving one equation applicable to both kind of substances, those which expand on melting and those, relatively more rare, which contract in the same process. Of course, equation (24) reduces to equation (23) if the simplest approximation $i=1$ is considered. In general equations (23) and (24) yield values of the fusion pressure which lay within \pm 6 per cent of the measured pressure in the immediate vicinity of the reference temperature $T_{0}$. At higher temperatures, of the order of 2 to $3 \cdot T_{0}$ (at which the fusion pressure reaches $10^{3} \mathrm{MPa}$ and much higher), the deviations in $p$ become lower, not exceeding \pm 3 per cent, as shown in figure 4. Important exceptions among the test substances used in this work are argon and mercury, for which the corresponding pressure deviation are always much smaller ( \pm 1 to \pm 2 per cent at the most). For these two substances abundant information of high quality on the ancillary data needed is available in the literature. For the calculations involving (solid + liquid) equilibria, either the triple-point or the normal melting point are convenient choices as reference $\left(p_{0}, T_{0}\right)$. Both have been used in this work according to the availability of accurate data in the literature. While the uncertainty attached to the value of $p_{0}$ has no influence on the results of the calculations, uncertainties of $\pm 0.1 \mathrm{~K}$ in the reference temperature $T_{0}$ yield deviations of up to \pm 4 per cent in the calculated values of the fusion pressure $p$, at temperatures lower than $1.2 \cdot T_{0}$. At temperatures higher than this the uncertainty decreases markedly. For some substances, e.g. the rare gases, and water, the difference in the molar volumes of the two phases at the reference point can be assessed from experimental data for each one of the phases at equilibrium but in many cases that difference has been reported directly as the change $\Delta_{\mathrm{cr}}^{1} V_{\mathrm{m}}$ along the fusion line. Whatever the form of the original data, uncertainties in this quantity give 


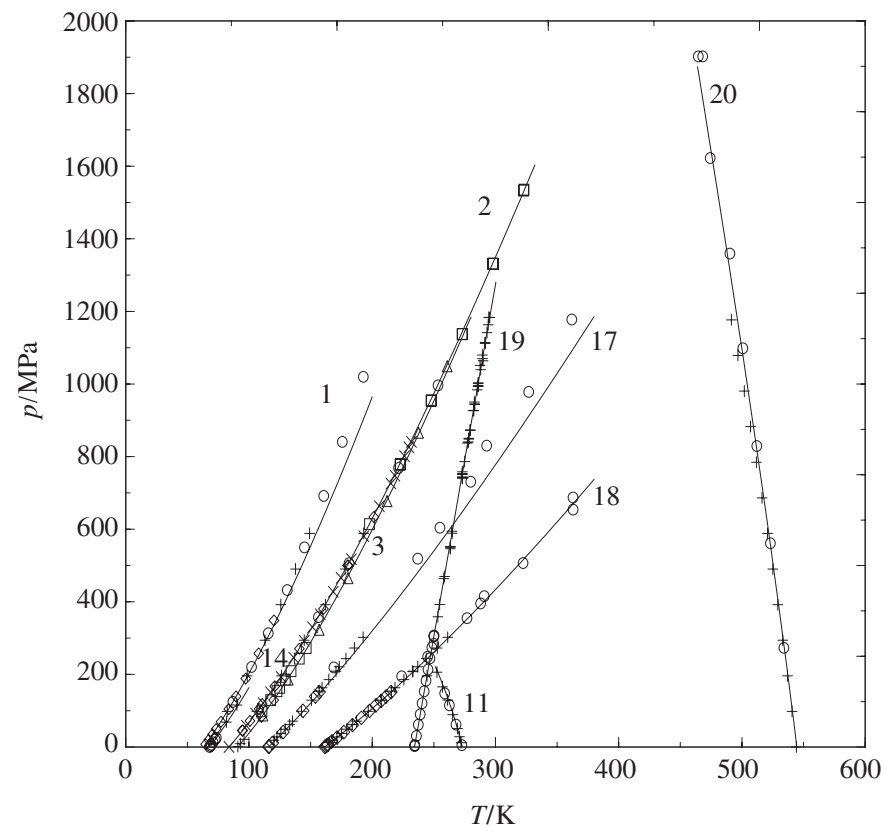

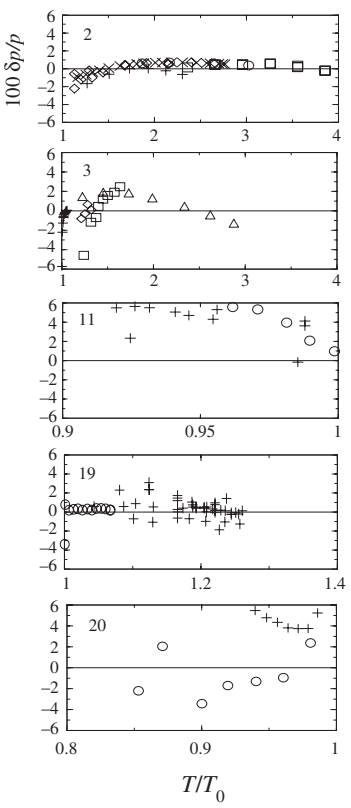

b

FIGURE 4. a, Fusion pressure $p$ plotted against temperature $T . \mathrm{b}$, Deviation plot of the fusion pressure against a reduced temperature $T / T_{0}$, where $T_{0}$ is a reference temperature taken as the triplepoint temperature or the normal melting temperature; $\delta p=p_{\text {calc }}-p$, where $p_{\text {calc }}$ is calculated from equation (23) for substances that expand on melting, or from equation (24) for substances that contract on melting, and $p$ is the experimental fusion pressure at the same temperature. Note the different scales for $T / T_{0}$; Legend: curves obtained from equation (23) for substances that expand on melting, or from equation (24) for substances that contract on melting; 1, nitrogen: O, Cheng et al. ${ }^{(89)} ;+$, Bridgman ${ }^{(90)} ; \diamond$, Grilly and Mills ${ }^{(91)} ; 2$, argon: O, Cheng et al. ${ }^{(92)}$; + , Bridgman ${ }^{(90)} ; \diamond$, Crawford and Daniels ${ }^{(93)} ; \square$, Stichov and Fedosimov ${ }^{(94)} ; \times$, Hardy et al. ${ }^{(95)}$; 3, methane: $\triangle$, Cheng et al. ${ }^{(89)} ; \diamond$, Nunes da Ponte and Staveley ${ }^{(96)} ; \square$, Stryland et al. ${ }^{(97)}$; 11, water: (ice I): O, Henderson and Speedy ${ }^{(98)} ;+$, Bridgman ${ }^{(99)} ; 14$, carbon monoxide: O, Clusius et al. ${ }^{(100)} ;+$, Barreiros et al. ${ }^{(101)} ; 17$, krypton: O, Lahr and Eversole ${ }^{(102)} ;+$, Stryland et al. ${ }^{(97)}$; $\diamond$, Michels and Prins ${ }^{(103)} ; 18$, xenon: same as for krypton; 19, mercury: O, Michels et al. ${ }^{(104)} ;+$, Bridgman $^{(105)} ; 20$, bismuth: $O$, Kennedy and Newton ${ }^{(106)} ;+$ Bridgman $^{(107)}$.

origin to deviations of the same relative magnitude in the estimated fusion pressure. The heat capacities of the equilibrium phases (liquid and solid) at the reference point used in this study have seldom been measured. However, short extrapolations of $C_{p, \mathrm{~m}}^{\mathrm{cr}}$ and $C_{p, \mathrm{~m}}^{1}$ as functions of temperature to $T_{0}$ yield values of $\Delta_{\mathrm{cr}}^{1} C_{p, \mathrm{~m}}\left(p_{0}, T_{0}\right)$ affected by estimated uncertainties of \pm 2 per cent, from which a maximum deviation of \pm 1 per cent should be expected in the calculated fusion pressure by using equations (23) and/or (24). The difference in the heat capacities determines the curvature of the temperature dependence of the fusion pressure line through term $\left(F_{\mathrm{f}} T \ln T\right)$. Due to the scarcity of data on heat 


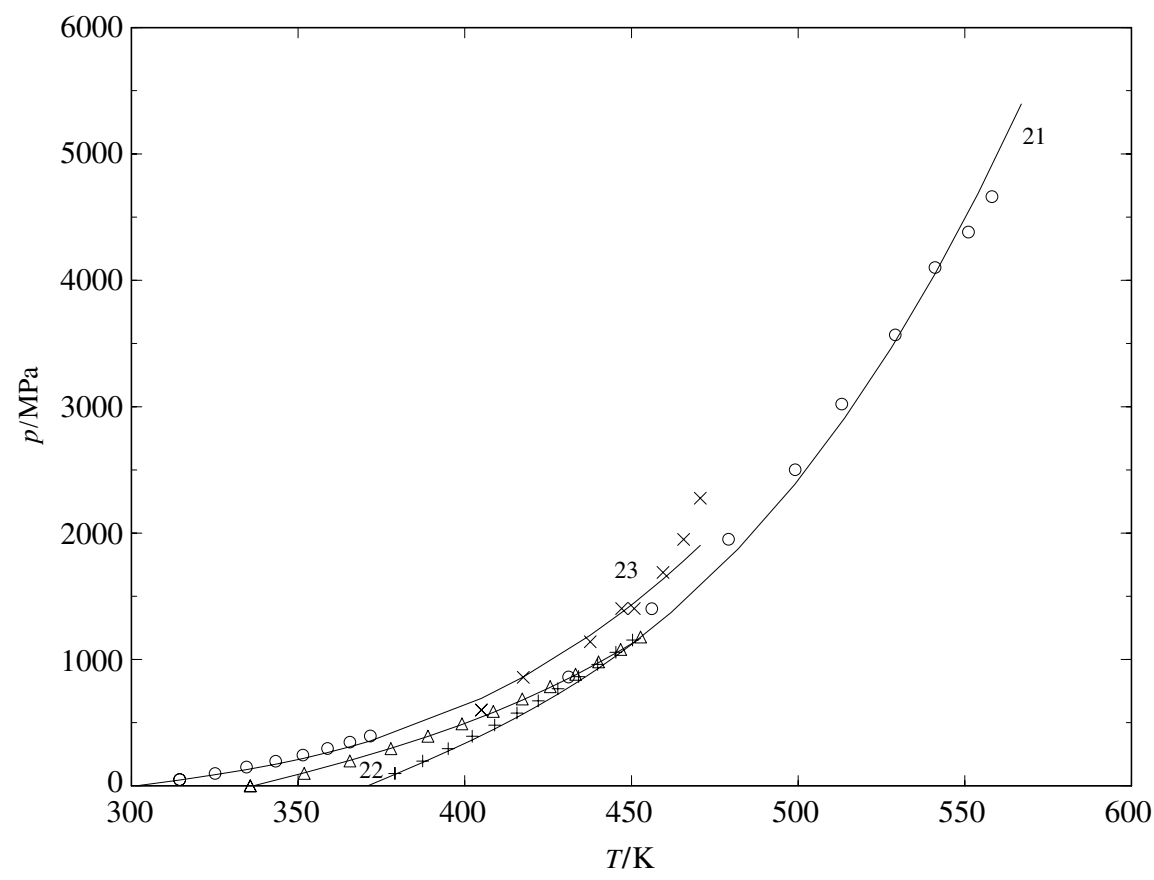

FIGURE 5. Fusion pressure $p / \mathrm{MPa}$ plotted against temperature $T / \mathrm{K}$ for alkali metals. Legend: 21 , sodium: $O$, Kennedy and Newton ${ }^{(106)} ;+, \operatorname{Bridgman}^{(107,108)} ; 22$, potassium: $\triangle \operatorname{Bridgman}^{(108)}$; 23, caesium (cr I): $\bigcirc$, Bridgman ${ }^{(109)} ; \times$, Kennedy and Newton ${ }^{(106)}$. Curves calculated from equations (23) and (43) using $\Delta_{\mathrm{cr}}^{1} \mathrm{c}_{2}=0.7,0.6$, and 1.2 for $\mathrm{Na}, \mathrm{K}$, and $\mathrm{Cs}$, respectively.

capacities along the fusion curve the (necessary) approximation embodied in equation (27) limits the range of application of equations (23) and (24) since for many substances the experimental information available indicates that $\Delta_{\mathrm{cr}}^{1} c_{1}=\Delta_{\mathrm{cr}}^{1} C_{p, \mathrm{~m}}\left(p_{0}, T_{0}\right)$ is nearly zero. This implies that a linear dependence of the fusion pressure on temperature is obtained from equation (23), a situation not always observed in practice. For instance, the alkali metals exhibit marked curvature in their respective fusion lines, a feature that can be accounted for if the linear dependence

$$
\Delta_{\mathrm{cr}}^{1} C_{p, \mathrm{~m}}\left(p_{0}, T\right)=\Delta_{\mathrm{cr}}^{1} c_{1}+\Delta_{\mathrm{cr}}^{1} c_{2}\left(T-T_{0}\right),
$$

is considered instead of equation (12). Obviously this would bring an additional term (in $T^{2}$ ) to the right-hand side of equation (23). Unfortunately, experimental data enabling the determination of the parameter $\Delta_{\mathrm{cr}}^{1} c_{2}$ have not been found in the literature. However, by assuming relatively small values for this parameter the experimental trend of the fusion curves can be described, as shown in figure 5. For the test substances examined in this study the uncertainty attached to their respective enthalpy of fusion at the reference point is in no case larger than \pm 1 per cent. Considering this figure the deviation in the calculated fusion pressure is not larger than \pm 1 per cent near the reference point, and decreases to 


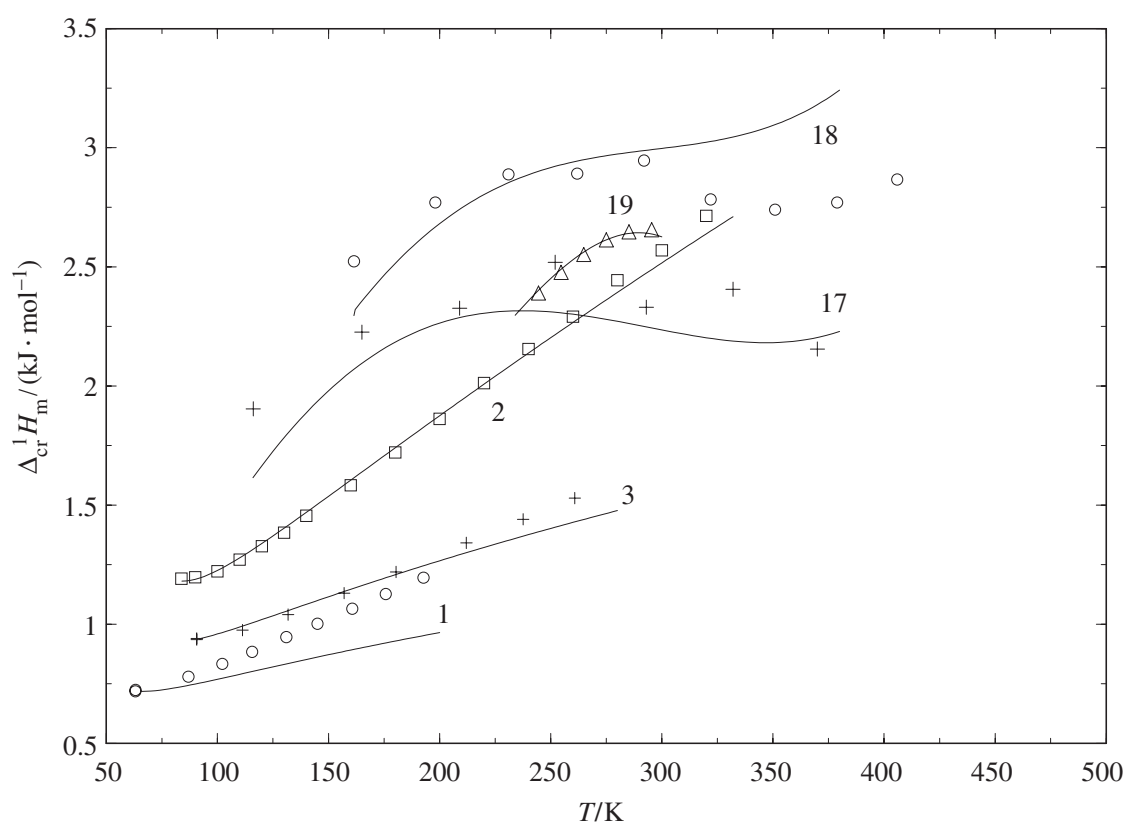

FIGURE 6. Molar enthalpy of fusion $\Delta_{\mathrm{cr}}^{1} H_{\mathrm{m}} /\left(\mathrm{kJ} \cdot \mathrm{mol}^{-1}\right)$ plotted against temperature $T / \mathrm{K}$. Legend: curves calculated from equation (23). 1, nitrogen: $\bigcirc$, Cheng et al. ${ }^{(89)} ; 2$, argon: $\square$, Crawford ${ }^{(110)}$; 3, methane: +, Cheng et al. ${ }^{(89)}$; 17, krypton: + , Lahr and Eversole ${ }^{(102)} ; 18$, xenon: O, Lahr and Eversole $^{(102)} ; 19$, mercury: $\triangle$, $\operatorname{Bridgman}^{(105)}$.

\pm 0.5 per cent at higher temperatures (or at lower temperatures if the substance contracts on melting).

Estimates of $\Delta_{\mathrm{cr}}^{1} H_{\mathrm{m}}(T)$ were carried out much in the same way as those for the other phase equilibria previously reported in this work. Comparison with literature values is made in figure 6.

For substances which expand on melting the empirical equation named after Simon, ${ }^{(111)}$

$$
p=p_{0}+a\left\{\left(T / T_{\text {tr }}\right)^{c}-1\right\},
$$

where $a$ and $c$ are parameters obtained by fitting to experiment, has been extensively used. Voronel ${ }^{(112)}$ showed that equation (44) is obtained by admitting that $\Delta_{\mathrm{cr}}^{1} H_{\mathrm{m}} / \Delta_{\mathrm{cr}}^{1} V_{\mathrm{m}}$ is a linear function of the fusion pressure of the form

$$
\Delta_{\mathrm{cr}}^{1} H_{\mathrm{m}} / \Delta_{\mathrm{cr}}^{1} V_{\mathrm{m}}=(p+a) c .
$$

From our equation (23) one arrives at

$$
\begin{aligned}
\Delta_{\mathrm{cr}}^{1} H_{\mathrm{m}} / \Delta_{\mathrm{cr}}^{1} V_{\mathrm{m}}= & p-\left\{p_{0}-\Delta_{\mathrm{cr}}^{1} H_{\mathrm{m}}\left(p_{0}, T_{0}\right) / \Delta_{\mathrm{cr}}^{1} V_{\mathrm{m}}\left(p_{0}, T_{0}\right)\right\}+ \\
& \left\{\Delta_{\mathrm{cr}}^{1} c_{1} / \Delta_{\mathrm{cr}}^{1} V_{\mathrm{m}}\left(p_{0}, T_{0}\right)\right\}\left(T-T_{0}\right) .
\end{aligned}
$$

In spite of the apparent differences between these two expressions our calculations showed 
that for the test substances the ratio $\Delta_{\mathrm{cr}}^{1} H_{\mathrm{m}} / \Delta_{\mathrm{cr}}^{1} V_{\mathrm{m}}$ obtained from equation (46) is nearly a linear function of the fusion pressure. ${ }^{(3)}$

$($ SOLID + SOLID) EQUILIBRIA

The wide variety of solid $\rightarrow$ solid phase transition lines allied to the scarcity of accurate experimental data necessary for the calculations makes it difficult to test the equations found for the equilibria belonging to this class. Moreover, it is not easy to assess the errors attached to most measurements reported in the literature. This situation impairs the systematic study of the uncertainties in the derived quantities. Even so equation (23) written for solid + solid equilibria has been applied to a number of substances for which data of sufficient accuracy are available, and some general observations can be made from the results obtained. The reference coordinates $\left(p_{0}, T_{0}\right)$ have been taken as those of the various triple-points in each diagram, whichever the nature of the three phases at equilibrium. In general the molar volume changes $\Delta_{\mathrm{crI}}^{\mathrm{crI}} V_{\mathrm{m}}$ can be assessed by fitting of the reported molar volumes of the equilibrium phases to simple temperature or pressure polynomials. The situation is somewhat different in assessing the values of $\Delta_{\mathrm{crI}}^{\mathrm{crII}} C_{p, \mathrm{~m}}$. For most equilibria studied in this work this quantity has not been measured, as far as we are aware. In these cases it has been taken as zero (as suggested by a number of fusion equilibrium data). This approximation implies that the calculated transition lines should be straight. It is only when $\Delta_{\mathrm{crI}}^{\mathrm{crII}} C_{p, \mathrm{~m}} \neq 0$ that the calculated lines can exhibit some curvature, in which case even modest values of the heat capacity change account for the observed nonlinear pattern of the transition lines. For the substances tested in this work the equilibrium pressures have been estimated with uncertainties not exceeding \pm 6 per cent of the experimental values as illustrated in figure 7.

\section{Conclusions}

In this paper a consistent set of equations for first-order transition $(p, T)$ curves of pure substances has been established from the exactly integrated form of the Clapeyron equation due to Mosselman et al. ${ }^{(2)}$ In general, the application of the equations proposed here requires the knowledge of only one (reference) point on the respective equilibrium line, of the corresponding enthalpy of transition, and some ancillary data (molar volumes and molar heat capacities of the equilibrium phases). Since no fitting to $(p, T)$ experimental data is necessary, this procedure can be regarded as a method for estimating a priori the phase equilibrium curves. The equations presented in this work provide a comprehensive, systematic means to describe the two-phase transition lines over large temperature ranges within a few per cent of the measured equilibrium pressures. As far as we are aware no prior quantitative, analytical treatment of (solid + solid) equilibria has been reported in the literature. Some derived phase transition properties, among which the enthalpies of transition as functions of temperature, are readily obtained within experimental error from the equations derived in this work. The enthalpy of sublimation at $T \rightarrow 0$ is also easily obtained. We believe that the method and the results presented here can be explored further in many important directions. 

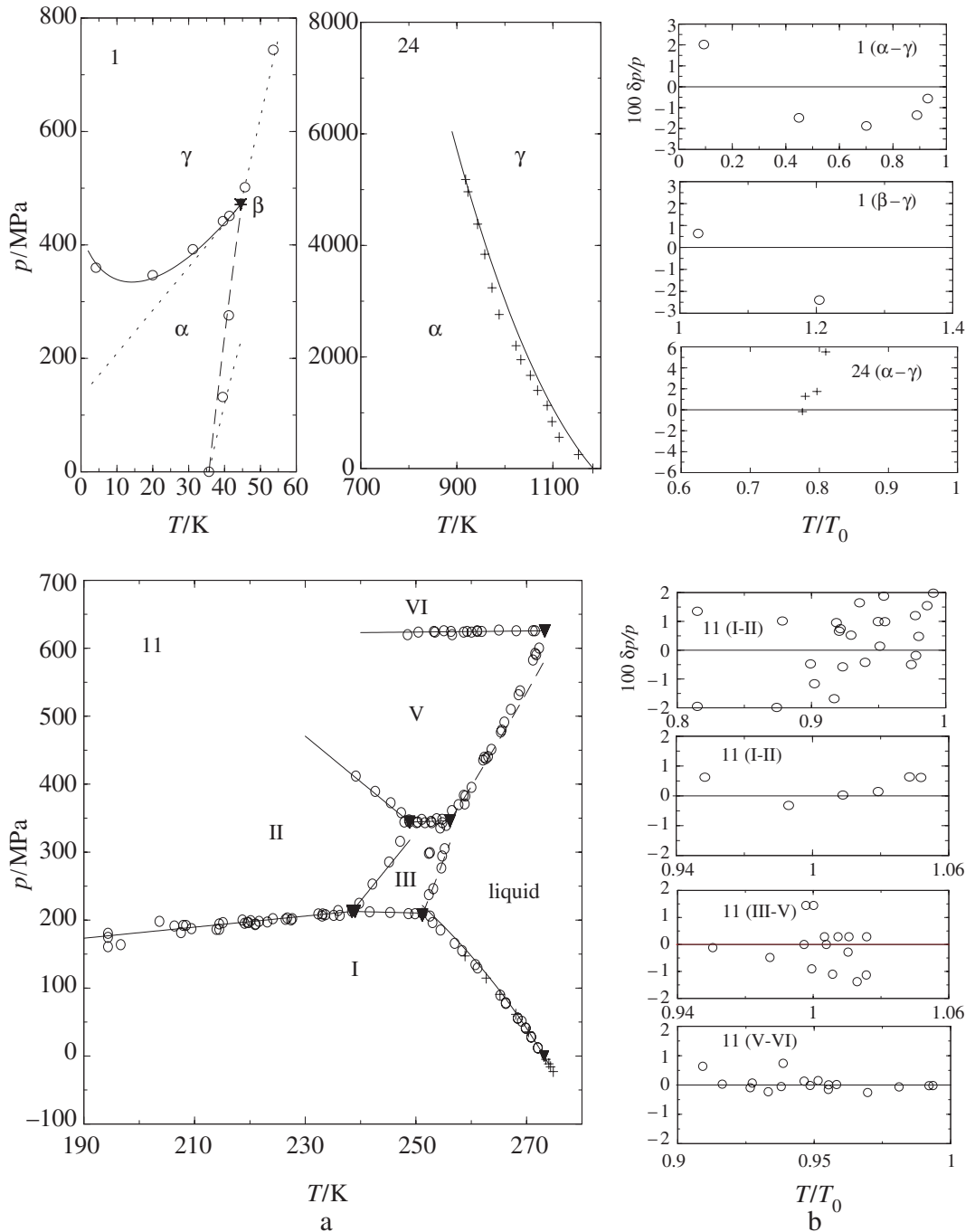

FIGURE 7. a, (Solid + solid) equilibrium pressure $p$ plotted against temperature $T . \mathrm{b}$, Deviation plot of the (solid + solid) equilibrium pressure against a reduced temperature $\left(T / T_{0}\right) ; T_{0}$ is a reference temperature taken as that of one of the triple-points; $\delta p=p_{\text {calc }}-p$, where $p_{\text {calc }}$ is calculated from equation (23) and $p$ is the experimental solid + solid equilibrium pressure at the same temperature. Legend: $\boldsymbol{\nabla}$, triple-points; 1 , nitrogen: $\bigcirc$, Swenson ${ }^{(113)}$; the long-dashed line is the $\alpha+\beta$ phase separation; the short-dashed lines are calculated from equation (23) using $\Delta_{\mathrm{crI}}^{\mathrm{crII}} \mathrm{C}_{p, \mathrm{~m}}=0$; the full line is calculated from equation (23) using a tentative value of $\Delta_{\mathrm{crI}}^{\mathrm{crI}} \mathrm{C}_{p, \mathrm{~m}}=$ $1.1 \mathrm{~J} \cdot \mathrm{mol}^{-1} \cdot \mathrm{K}^{-1} ; 24$, iron: + , Kennedy and Newton ${ }^{(106)}$; curve calculated from equation (23); 11, water: $\bigcirc$, Bridgman ${ }^{(99)} ;+$, Henderson and Speed ${ }^{(98)}$; all curves calculated from equation (23), except that for the equilibrium crI +1 which was calculated from equation (24) as in figure 4; dashed lines obtained considering that $\Delta_{\mathrm{cr}}^{1} \mathrm{C}_{p, \mathrm{~m}}$ for the equilibria $\mathrm{crIII}+1$ and $\mathrm{crV}+1$ has the same value as that for $\mathrm{crI}+1$. 


\section{REFERENCES}

1. Ziegler, W. T.; Mullins, J. C.; Kirk, B. S. Calculation of the Vapor Pressure and Heats of Vaporization and Sublimation of Liquids and Solids, Especially Below One Atmosphere Pressure. I. Ethylene. Technical Report No. 1. Georgia Institute of Technology: Atlanta. 1962

2. Mosselman, C.; van Vugt, W. H.; Vos, H. J. J. Chem. Eng. Data 1982, 27, 246-251.

3. Ferreira, A. G. M. Estudo Termodinâmico do Equilíbrio de Fases de Substâncias Puras. Tese de Doutoramento. Vol. I and II. Universidade de Coimbra: 1996.

4. Goldberg, R. N.; Weir, R. D. Pure Appl. Chem. 1992, 64, 1545-1562.

5. Staveley, L. A. K.; Lobo, L. Q.; Calado, J. C. G. Cryogenics 1981, 21, 131-144.

6. Keesom, W. H.; Bijl, A. Physica 1937, 4, 305-310.

7. Giauque, W. F.; Clayton, J. O. J. Am. Chem. Soc. 1933, 55, 4875-4889.

8. Flubacher, P.; Leadbetter, A. J.; Morrison, J. A. Proc. Phys. Soc. (London) 1961, 78, 1449-1461.

9. Chen, H. H.; Lim, C. C.; Aziz, R. A. J. Chem. Thermodynamics 1978, 10, 649-659.

10. Lemming, C. W.; Pollack, G. L. Phys. Rev. 1970, 2, 3323-3330.

11. Levenson, L. L. C. Rend. Acad. Sci. Paris 1967, 265B, 1217-1220.

12. Tickner, A. W.; Lossing, F. P. J. Chem. Phys. 1951, 5, 733-740.

13. Rossini, F. D. Selected Values of Physical and Thermodinamic Properties of Hydrocarbons and Related Compounds. Carnegie Press: Pittsburg. 1953 (cf. Properties of Materials at Low Temperature. Phase 1. Jonhson, V. J.: editor. Pergamon: New York. 1961).

14. Bigeleisen, J.; Fuks, S.; Ribnikar, S. V.; Yato, Y. J. Chem. Phys. 1977, 66, 1689-1700.

15. Chu Liang, S. J. Phys. Chem. 1952, 56, 660-662.

16. Giauque, W. F.; Wiebe, R. J. Am. Chem. Soc. 1928, 50, 101-122.

17. Chihara, H.; Inaba, I. J. Chem. Thermodynamics 1976, 8, 915-934.

18. Ser, F.; Larher, Y. J. Chem Thermodynamics 1990, 22, 407-412.

19. Atake, T.; Chihara, H. Bull. Chem. Soc. Japan 1974, 47, 2126-2136.

20. Blue, R. W.; Giauque, W. F. J. Am. Chem. Soc. 1935, 57, 991-997.

21. Terlain, A. J. Chim. Phys. 1983, 80, 805-808.

22. Bryson, C. E.; Cazcarra, V.; Levenson, L. L. J. Chem. Eng. Data 1974, 19, 107-110.

23. Giauque, W. F.; Egan, C. J. J. Chem Phys. 1937, 5, 45-54.

24. Ambrose, D. Trans. Faraday Soc. 1956, 52, 772-781.

25. Angus, S.; Armstrong, B.; Reuck, K. M. International Thermodynamic Tables of the Fluid State-3 Carbon Dioxide. Pergamon: Oxford. 1976.

26. Overstreet, R.; Giauque, W. F. J. Am. Chem. Soc. 1937, 59, 254-259.

27. Jackowski, A. W. J. Chem. Thermodynamics 1974, 6, 49-52.

28. Jancso, G.; Papezin, J.; Van Hook, W. A. J. Phys. Chem. 1970, 74, 2984-2989.

29. Ambrose, D. Pure Appl. Chem. 1977, 49, 1437-1464.

30. Keenan, J. H.; Keyes, F. G.; Hill, P. G.; Moore, J. G. Steam Tables. Wiley: New York. 1969.

31. De Kruif, C. G.; Kuipers, T.; Van Miltenburg, J. C.; Sckaake, R. C. F.; Stevens, G. J. Chem. Thermodynamics 1981, 13, 1081-1086.

32. Bradley, R. S.; Cleasby, T. G. J. Chem. Soc. 1953, 1690-1692.

33. Ambrose, D.; Lawrenson, I. J.; Sprake, C. H. S. J. Chem. Thermodynamics 1975, 7, 1173-1176.

34. Sinke, G. C. J. Chem. Thermodynamics 1974, 6, 311-316.

35. Ziegler, W. T.; Mullins, J. C.; Kirk, B. S. Calculation of the Vapor Pressure and Heats of Vaporization and Sublimation of Liquids and Solids, Especially Below One Atmosphere. IV. Nitrogen and Fluorine. Technical Report No. 1. Georgia Institute of Technology: Atlanta. 1963.

36. Ziegler, W. T.; Mullins, J. C.; Kirk, B. S. Calculation of the Vapor Pressure and Heats of Vaporization and Sublimation of Liquids and Solids, Especially Below One Atmosphere Pressure. II. Argon. Technical Report No. 2. Georgia Institute of Technology: Atlanta. 1963.

37. Ziegler, W. T.; Mullins, J. C.; Kirk, B. S. Calculation of the Vapor Pressure and Heats of Vaporization and Sublimation of Liquids and Solids, Especially Below One Atmosphere Pressure. III. Methane. Technical Report No.3. Georgia Institute of Technology: Atlanta. 1962. 
38. Ziegler, W. T.; Kirk, B. S.; Mullins, J. C.; Berquist, A. R. Calculation of the Vapor Pressure and Heats of Vaporization and Sublimation of Liquids and Solids, Especially Below One Atmosphere Pressure. VII. Ethane. Technical Report No. 2. Georgia Institute of Technology: Atlanta. 1963.

39. Eucken, A.; Donath, E. Z. Phys. Chem. 1926, 124, 181-199.

40. Mullins, J. C.; Kirk, B. S.; Ziegler, W. T. Calculation of the Vapor Pressure and Heats of Vaporization and Sublimation of Liquids and Solids, Especially Below One Atmosphere. V. Carbon Monoxide and Carbon Dioxide. Technical Report No. 2. Georgia Institute of Technology: Atlanta. 1963.

41. Newitt, D. M.; Pai, M. V.; Kuloor, N. R.; Huggill, J. A. W. Thermodynamic Functions of Gases$\mathrm{CO}_{2}$. Vol. 1. Din, F.: editor. Butterworths: London. 1962.

42. De Boer, J. H. Trans. Faraday Soc. 1936, 32, 10 (cf. reference 25).

43. Murata, S.; Sakiyama, M.; Seki, S. J. Chem. Thermodynamics 1982, 14, 707-721.

44. Yarbrough, D. W.; Tsai, C. H. Adv. Cryogenic Eng. 1978, 23, 602-610.

45. Angus, S.; Reuck, K. M.; Armstrong, B.; Jacobsen, R. T.; Stewart, R. B. International Thermodynamic Tables of the Fluid State—6 Nitrogen. Pergamon: Oxford. 1979.

46. Lennard-Jones, J. E. Proc. Phys. Soc. 1931, 43, 461-482.

47. Beaumont, R. H.; Chihara, H.; Morrison, J. A. Proc. Phys. Soc. 1961, 78, 1462-1481.

48. Horton, G. K. Am. J. Phys. 1968, 36, 93-119.

49. Gibbons, T. G.; Klein, M. C.; Murphy, R. D. Chem. Phys. Lett. 1973, 18, 325-328.

50. Tester, H. E. Thermodynamic Functions of Gases-Methane. Vol. 3. Din, F.: editor. Butterworths: London. 1961.

51. Colwell, J. H.; Gill, E. K.; Morrison, J. A. J. Chem. Phys. 1963, 39, 635-653.

52. Jacobsen, R. T.; Jahangiri, M.; Stewart, R. B.; McCarty, R. D. International Thermodynamic Tables of The Fluid State-2 Ethylene. Blackwell: Oxford. 1988.

53. Auer, W.; Schäfer, K. Landolt-Börnstein : Zahlenwerte und Funktionen aus Physik, Chemie, Astronomie, Geophysic und Technik. Vol. II. Schäfer, K.; Lax, E.: editors. Springer: Berlin. 1961 (cf. reference 25)

54. Shipman, L. L.; Burgess, A. W.; Scheraga, H. A. J. Phys. Chem. 1976, 80, 52-54.

55. Eisenberg, D.; Kauzman, W. The Structure and Properties of Water. Oxford University Press: London. 1969.

56. Moelwyn-Hughes, E. A. Physical Chemistry: 2nd edition. Pergamon Press: Oxford. 1961.

57. Partington, J. R. An Advanced Treatise on Physical Chemistry. Vol. 2. Longmans: New York. 1951.

58. Wagner, W. Cryogenics 1973, 13, 470-482.

59. Kleinrahm, R.; Wagner, W. J. Chem. Thermodynamics 1986, 18, 739-760.

60. Prydz, R.; Goodwin, R. D. J. Chem. Thermodynamics 1972, 4, 127-133.

61. Douslin, D. R.; Harrison, R. H. J. Chem. Thermodynamics 1976, 8, 301-330.

62. Michels, A.; Wassenaar, T. Physica 1950, 16, 221-224.

63. Egan, C. J.; Kemp, J. D. J. Am. Chem. Soc. 1937, 59, 1264-1268.

64. Douslin, D. R.; Harrison, R. H. J. Chem. Thermodynamics 1973, 5, 491-512.

65. Straty, G. C.; Tsumura, R. J. Res. Natl. Bur. Stand. 1976, 80A, 35-36.

66. Carruth, G. F.; Kobayashi, R. J. Chem Eng. Data 1973, 18, 115-126.

67. Thomas, W. Progr. Int. Res. Thermodynamics and Trasport Properties. Masi, J. F.; Tsai, D. H.: editors. Princeton University: 1962.

68. Henderson, C.; Lewis, D. G.; Prichard, P. C.; Staveley, L. A. K.; Fonseca, I. M. A.; Lobo, L. Q. J. Chem. Thermodynamics 1986, 18, 1077-1088.

69. Beattie, J. A.; Lawrence, C. K. J. Am. Chem. Soc. 1930, 52, 6-14.

70. Baehr, H. D.; Garnjost, H.; Pollak, R. J. Chem. Thermodynamics 1976, 8, 113-119.

71. Cragoe, C. S.; Meyers, C. H.; Taylor, C. S. J. Am. Chem. Soc. 1920, 42, $206-229$.

72. Streatfeild, M. H.; Henderson, C.; Staveley, L. A. K.; Ferreira, A. G. M.; Fonseca, I. M. A.; Lobo, L. Q. J. Chem. Thermodynamics 1987, 19, 1163-1171.

73. Ambrose, D. J. Chem. Thermodynamics 1981, 13, 1161-1167. 
74. Ambrose, D. J. Chem. Thermodynamics 1987, 19, 1007-1008.

75. Golding, P. D.; Machin, W. D. J. Chem. Soc., Faraday Trans. 1987, 83, 2719-2726.

76. Sato, H.; Uematsu, M.; Watanabe, K.; Saul, A.; Wagner, W. J. Phys. Chem. Ref. Data 1988, 17, $1439-1540$

77. Michels, A.; Wassenaar, T.; Zwietering, T. N. Physica 1952, 18, 160-162.

78. Clayton, J. O.; Giauque, W. F. J. Am. Chem. Soc. 1932, 54, 2610-2626.

79. Wagner, W.; Ewers, J.; Pentermann, W. J. Chem. Thermodynamics 1976, 8, 1049-1060.

80. Hilsenrath, J. NBS Circ. 564. 1955, 427 (cf. Properties of Materials at Low Temperature. Phase 1. Jonhson, V. J.: editor. Pergamon: New York. 1961).

81. Kay, W. B.; Rambosek, G. M. Ind. Eng. Chem. 1953, 45, 221-226.

82. Clarke, E. C. W.; Glew, D. N. Can. J. Chem. 1970, 48, 764-775.

83. Giauque, W. F.; Blue, R. W. J. Am. Chem. Soc. 1936, 58, 831-842.

84. Reid, R. C.; Prausnitz, J. M.; Poling, B. E. The Properties of Gases and Liquids: 4th edition: McGraw-Hill: New York. 1987.

85. Ambrose, D. Equations for the Correlation and Estimation of Vapour Pressures. Report CHEM 114 NPL: Teddington, U. K. 1980.

86. Pollack, G. L. Rev. Mod. Phys. 1964, 36, 748-791.

87. Cragoe, C. S. International Critical Tables of Numerical Data, Physics, Chemistry and Technology. Vol. III. McGraw-Hill: New York. 1928.

88. Frost, A. A.; Kalkwarf, D. R. J. Chem. Phys. 1953, 21, 264-267.

89. Cheng, V. M.; Daniels, W. B.; Crawford, R. K. Phys. Rev. 1975, 11, 3972-3975.

90. Bridgman, P. W. Phys. Rev. 1934, 46, 930-933.

91. Grilly, E. R.; Mills, R. L. Phys. Rev. 1957, 105, 1140-1145.

92. Cheng, V. M.; Daniels, W. B.; Crawford, R. K. Phys. Lett. 1973, 43A, 109-110.

93. Crawford, R. K.; Daniels, W. B. J. Chem. Phys. 1969, 50, 3171-3183.

94. Stishov, S. M.; Fedosimov, V. I. J. E. T. P. Lett. 1971, 14, 217-220.

95. Hardy, W. H.; Crawford, R. K.; Daniels, W. B. J. Chem. Phys. 1971, 54, 1005-1110.

96. Nunes da Ponte, M.; Staveley, L. A. K. J. Chem. Thermodynamics 1976, 8, 1109-1110.

97. Stryland, J. C.; Crawford, J. E.; Mastoor, M. A. Can. J. Phys. 1960, 38, 1546-1547.

98. Henderson, J.; Speedy, R. J. J. Phys. Chem. 1987, 91, 3069-3072.

99. Bridgman, P. Proc. Am. Acad. Arts. Sci. 1911, 47, 441-561.

100. Clusius, K.; Piesbergen, U.; Varde, E. Helv. Chem. Acta 1960, 43, 2059-2063.

101. Barreiros, S. F.; Calado, J. C. G.; Nunes da Ponte, M. J. Chem. Thermodynamics 1982, 14, 1197-1198.

102. Lahr, P. H.; Eversole, W. G. J. Chem. Eng. Data 1962, 7, $42-47$.

103. Michels, A.; Prins, C. Physica 1962, 28, 101-116.

104. Michels, A.; Wassenaar, T.; Blaise, B. Physica 1942, 9, 574-576.

105. Bridgman, P. W. Proc. Am. Acad. Arts. Sci. 1911, 47, 347-438.

106. Kennedy, G. C.; Newton, R. C. Solids Under Pressure. Paul, W.; Warschauer, D. M.: editors. McGraw-Hill: New York. 1963.

107. Bridgman, P. W. Phys. Rev. 1915, 6, 1-33.

108. Bridgman, P. W. Phys. Rev. 1914, 3, 126-203.

109. Bridgman, P. W. Proc. Am. Acad. Arts. Sci. 1925, 60, 385-421.

110. Crawford, R. K. Rare Gas Solids. Vol. II. Klein, M. L.; Venables, J. A.: editors. Academic Press: New York. 1977.

111. Simon, F. E.; Glatzel, G. Z. Anorg. Allg. Chem. 1929, 178, 309-316.

112. Voronel, A. V. Sov. Phys. Technol. Phys. 1958, 3, 2408-2411.

113. Swenson, C. A. J. Chem. Phys. 1955, 23, 1963-1964.

(Received 16 August 2001; in final form 10 September 2001)

WE-318 